\title{
Exploring Second Life Applications for Electric Vehicle Batteries
}

\author{
Felix VUa, Melanie RAHIC ${ }^{\mathrm{a}}$, Koteshwar CHIRUMALLA ${ }^{\mathrm{a}, 1}$ \\ ${ }^{a}$ Mälardalen University, Eskilstuna, Sweden
}

\begin{abstract}
The purpose of the study is to explore an economically viable second life applications for electric vehicles (EV) batteries. There is a common consensus in the automotive industry that the reuse of retired EV batteries - often referred as a second life of a battery - can provide greater economic and sustainability benefits. Although literature acknowledged potential business opportunities with batteries' second life, there are still a lot of uncertainties, making success difficult to realize. In particular, identification of a profitable second life application with a right business model in the battery value chain has become a key success factor. Therefore, a case study, with a mixed research approach, considering both qualitative and quantitative methods, has been conducted in a company that is one of the leading manufacturers in the heavy-duty industrial vehicle industry, which currently is developing their electric vehicle machines with a li-ion battery pack. The study generated and analyzed several different second life concepts to find the most economically viable second life applications. The analysis concluded three second life business concepts in the initial phase. In the later phases, individual business model canvases and different reverse logistics processes were created, mapped, compared, and validated through quantitative analysis. The analysis show that out of three concepts remanufacturing application proved to be the most applicable one for the case company, within a range of 15 years' time. The paper contributes to the theory of circular business models in the context of EV batteries.
\end{abstract}

Keywords. Electrification, EV batteries, Second life, Business model innovation, Circular economy.

\section{Introduction}

The companies in the automotive industry are increasingly shifting to electrification or electromobility in an effort to embrace alternative energy sources in place of combustion engines in order to reduce emissions and to increase efficiency. The climate goal for the transport sector in the European Union (EU) is a $65 \%$ CO2 emission reduction by 2050 compared to emissions in 1990 [1]. The corresponding target for Sweden is a 70\% emission reduction by 2030 compared to emissions in 2010 [2]. Recent years have seen a great market expansion of electric vehicles (EV) in the industry. In July 2018, Sweden had 55,000 EV, compared to 1,5 million worldwide - a number expected to reach 10,79 million by 2025 [3]. It was predicted that by 2040, more than half of new cars sold in the world will be EVs, with $70 \%$ of market share in EU, and over $50 \%$ in China [4]. With the emerging new technologies and new models, EV growth will be exponential in the coming years.

\footnotetext{
${ }^{1}$ Corresponding Author. koteshwar.chirumalla@mdh.se
} 
The electric battery pack (BP), the heart of the Electric Vehicles (EV), is normally powered by lithium ion (li-ion) batteries, which have an expected service life of 5 to 15 years. These EV li-ion batteries degrade over time, losing up to $20 \%-30 \%$ of their capacity after the expected service life. Although $70 \%-80 \%$ remains, due to safety reasons, the battery is no longer permitted in vehicle applications. By 2025, an estimated 250,000 metric tons of EV li-ion batteries will have reached end of life [5], capturing actual value from these retired $\mathrm{EV}$ batteries is the cornerstone for achieving sustainable development and even the success of EV initiatives and its market. Researchers claimed that the greatest sustainability and economic benefits can be achieved if retired batteries are first reused and then recycled [6] and moreover $85 \%$ of all EV batteries are suitable for a second life [7] . Hence, the concept of EV li-ion batteries' secondary life has become a critical research topic [8].

The potential second life applications could include less demanding, stationary, or high capacity applications, including peak shaving, renewable energy storage, and integration from solar panels and wind turbines, back-up power, grid services, power fork lifts, electric boats, and smaller applications such as bicycles, scooters, or assisting robots. The second life applications in the coming decades could help countries achieve renewable energy and greenhouse gas reduction goals faster and more cheaply than predicted. As EV batteries have optimal properties to be reused for energy storage with regard to their capacity and remaining life cycles [9], several demonstration projects worldwide are being produced with different types of business models [10]. The second life EV battery market is expected to grow to $\$ 4,2$ billion by 2025 [11]. In Europe, several vehicle manufacturers are exploring such emerging market opportunities in partnership with electric utilities as well as specialist third parties, installing used batteries primarily in different kinds of energy storage systems (ESS), ranging from small residential systems to larger containerized grid-scale solutions [11]. These systems are used for a variety of services, including time-shift management, frequency response, backup power, demand-side response, and auxiliary capacity.

Reserachers explored the topic of electric battery packs from different perspectives, which ranges from investigating a specific battery technology and related chemistry to identifying advanced digital services and new business models to implementing and assessing the usefulness of secondary applications. Although the existing knowlegde base shows proven evidences on potential business opportunities with batteries' second life, several vehicle manufacturers still face difficulties to identify the right second life applications related to their batteries, more specifically to identify a profitable business model concepts in the battery value chain.

The purpose of the study is explore an economically viable second life applications for electric vehicles (EV) batteries. The guiding research question for the study is as follows: which second life applications are economically viable for battery packs of electrified machines?

To address this purpose, a case study has been conducted in a company that is one of the leading manufacturers in the heavy-duty industrial vehicle industry, which currently is developing their electric vehicle machines with a li-ion battery pack. At the case company the concept is still in a research stage, indicating a need for a thorough investigation of the area and its potentiality. Several different second life concepts have been generated and analyzed to find the most economically viable second life applications. Based on the initial analysis, three second life business concepts are concluded. The final concept selection is based on all calculated numbers, including 
investment, total costs, payback years, return rate and profit factors within a range of 15 years. The analysis indicated that the remanufacturing application proved to be the most applicable one for the case company. Further, the results show that a good starting point would be to perform the remanufacturing in the current remanufacturing facility in Sweden. The paper contributes to the theory of circular business models in the context of EV batteries.

The remainder of the paper is organised as follows: The next section presents the theoretical background related to second life management of EV batteries. Section 3 describes the adopted research methodology for the investigation. Section 4 presents the results and finally section 5 summarise the conclusions.

\section{Theoretical background}

\subsection{Li-ion EV battery pack (BP)}

Li-ion batteries are classified as rechargeable secondary batteries, with a high energy density and efficiency features along with a long-life span. EV battery manufacturing includes lithium material extraction, component manufacturing (cathode, anode, electrolyte), cell manufacturing, battery module manufacturing, and BP assembly [12]. Batteries' electrolytes are essential for enabling high power and energy properties. In terms of safety, these electrolytes can be hazardous both for the consumer and during transportation, due to their flammability and instability properties [13]. To ensure the battery function's safety, the battery management system (BMS) is usually installed to control temperatures and avoid overheating and overcharge/overdischarge by regulating the charging rate [14]. More BMS data means the battery's state-of-health ( $\mathrm{SOH}$ ) can be determined more precisely. The degradation rate or $\mathrm{SOH}$ in batteries' first life depends on many factors, including consumer behaviour when charging/discharging and usage patterns (e.g., driving styles, technical specifications of battery, climate conditions where used; [10]).

\subsection{EV battery second life management}

Using EV batteries for a secondary application requires collecting and transporting the battery in the reverse logistics, which includes four process operations: a collection point, collective inspection area with selection and sorting processes, recovery, and redistribution [15]. Li-ion substances are classified as dangerous goods, implying damages for both humans and the environment. Hence, the reverse logistic system needs to consider this issue when transporting EV batteries [15]. The three remanufacture or repurposing processes for dealing with second life batteries from EV [8] are direct reuse, module dismantle, and cell dismantle. A process for re-using components and materials is being developed [7]. Yet data on the remanufacturing process of EV li-ion batteries and its costs are lacking [16]. Rohr et al. [16] mapped the remanufacturing process, which includes disassembling and inspecting the BP, testing electronics and the BMS, remanufacturing the frame/housing, and cleaning initial components. The batteries' configurations depend on the battery type, resulting in a particular remanufacturing process [7] [17]. Remanufacturing activities are often performed by OEMs as they have the technical knowledge required. To reduce remanufacturing costs, an EV battery 
management system with the ability to store all data at the individual battery cell level, including temperature, voltage, depth of discharge, overcharging, and short circuits, must be developed [10].

Repurposing is the process of transforming a used EV BP to fit another application, unlike remanufacturing, where it is reused in the same application [18]. The repurposing process requires disassembling the batteries to the cell level, testing the cells' $\mathrm{SOH}$, and reassembling them to fit the new application. Another step is the control system; both hardware and software must be suited for the new application [7] [16] [17]. It is important to identify areas complementary to the demands of automotive applications, with lower demands on battery performance. A good understanding of battery usage history during the battery pack's first life is necessary as second life performance is highly dependent on these usage patterns [19]. Monitoring the batteries and using a highly qualified battery selection process are crucial for the successful second life application. In the power system, reused batteries could provide benefits at different levels: as a stand-alone solution (off- grid), at an end-user's place, or at different positions in the network (e.g., the distribution or transmission level). Casals et al. [8] defined many challenges in finding the right conditions for reusing batteries, especially from an economic perspective, even though the lifetime is prolonged by four years. However, economic conditions (e.g., for offering demand-response services to the electricity market) are critical. Reid and Julve [10] identified three critical processes: apply big data to predict battery degradation as a function of duty cycle, temperature, and time; understand how drivers make automotive battery replacement decisions to estimate when batteries will be available for second uses; and estimate battery degradation, dependent on factors like breadth of duty cycles and climate environments. They also pointed out four factors to boost batteries' second life: adapt appropriate regulations, increase pilot projects and government support, set remanufacturing standards/standardization process, and make battery data available.

Enabling the transition to the circular economy with reuse and recycling requires specific product designs and business models [20]. A business model describes the underlying logic an organization uses to create, deliver, and capture value to customers [21]. Jiao and Evans [22] identified three important factors essential for functioning second life business models: battery ownership, inter-industry partnerships, and policy support. Naor et al. [23] suggested that servitized business models would lead to better affordability and control of the batteries at the end of their lifecycles, for the further reuse. Bocken et al. [20] proposed the "slowing resource loop" concept as a product design strategy closer to the second life concept. "Slowing" refers to the prolonged use and reuse of goods over time, through the design of long-life goods and product life extension. The authors recommended four business model strategies for slowing loops: access and performance, extended product value, classic long life, and encouraged sufficiency. Olsson et al. [6] showed that, although several stakeholders see potential in second life, various barriers exist, many of which are of an organizational and cognitive nature rather than the technology dimension. Cognitive barriers include not being interested in new business models or not finding enough value in second life solutions; organizational barriers relate to investment risks and legal issues.

In summary, the repurposing of retired batteries is still rare in the EV industry. Most practices are merely for demonstration purposes. The current research into EV batteries' remanufacturing and repurposing processes and their economic viability and related cost aspects require further research. 


\section{Reseach methodology}

The case study [24] was performed at a leading company in the heavy-duty vehicle industry that manufactures components including axles and transmissions such as wheel loaders and dump trucks. One of many solutions that the company provides are financing and services to over 200 dealers located in 145 different countries. The company is a strong and a leading company with a focus on zero emissions and sustainability. At the case company the concept is still in a research stage indicating the need for a detail investigation. The abductive approach [25] was more suitable for the study since the topic of investigation is new and considering it as a concept for the future, it is not possible to collect all the necessary empirical data from the field or from a real-life context. The study also adopted a mixed research approach, considering both qualitative and quantitative methods.

\subsection{Research process}

The research was conducted in six main steps as shown in below Figure 1.

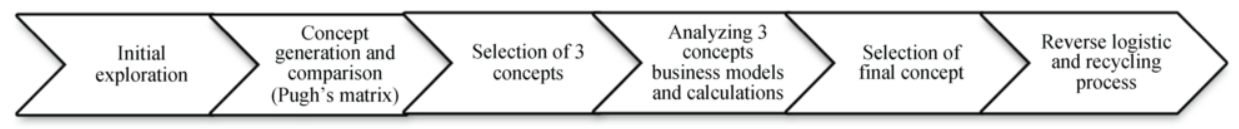

Figure1. The outline of the research process in six steps

The first step of the research process is constructing a literature review based on collected articles in the field of EV li-ion batteries. In order to strengthen the literature review, additional data has been gathered through both primary and secondary data. The primary data consists of technical information from the case company as well as numerical data and interviews. Whereas the secondary data is gathered through scientific articles, conferences and public governmental information. Methods such as brainstorming, mind mapping, Pugh's matrix and calculations have been used to chart and clarify the data. Based on the theory of new and existing concepts, business models and financial calculations have been provided to enhance the possible benefits for the case company.

Several suggestions have been presented for the case company and thereafter delimited to only analyse three concepts, considering their business aspect and logistic values. Thereafter, a beginning of the collection of the data was performed, specifically data from the case company by utilizing methods such as semi-structured and unstructured interviews, accessing reports and information about batteries, cost and price data, expected forecast data, volume percentages of $\mathrm{EV}$, remanufacturing and repurposing cost information including process steps and times.

After the information were gathered from the case company, the brainstorming was implemented into the process and resulted in a number of ideas. These ideas were narrowed down to five determined concepts and later inserted into a Pugh's matrix with the purpose of concluding in three suitable concepts. The three appropriate concepts from the Pugh's matrix were presented in separate business model canvases. By creating separate business models for the three concepts a holistic view of the concepts was gained. When presenting the concepts for the case company the business model allowed researchers to summarize all factors in nine blocks, including value proposition, key 
partners, key activities, key resources, cost structure, customer relationship, channels, customer segments and revenue streams, resulting in a broader understanding for what each block involves. After presenting all blocks in the business model, researchers began to gather data in order to calculate the total cost, profit, investment and Return Rate (RR) of the three concepts. To calculate these different factors, specific mathematical functions and formulas were created for each concept, since they all differ from each other. The formulas were entered into Excel to create a collective line diagram that visualizes the calculations and the results for all concepts. By visualizing these calculations in the line diagram, researchers could essentially distinguish the concepts from each other and determine which of the three concepts would be ideal for a future investment. The result indicated in a concept that is the most appropriate for a secondary use, taking into deliberation that it presents a function with figures in terms of total costs and how much the concept could generate, which ultimately presents the most beneficial concept for the case company.

Together with the case company one of the three concepts was chosen based on its potential on the future market. This concept was evaluated from a logistic point of view, where researchers have examined the reverse logistics for the EV BP and how it will be redistributed into its second life. It also involves the placement of the processing facility, in consideration of the transportation possibilities. In the end, the study led to identify the most ideal concept based on the business model and the logistic perspective that must be functional for the concept to be feasible.

Primary sources, in terms of numerical data have been gathered from the case company, followed by a numerical analysis being the foundation for the financial calculations. Considering that the research is still in its early phases for the company, researchers have also collected secondary data through scientific publications and reports. The data was based on around 20 group meetings and unstructured interviews and five semi-structured interviews, involving for example global product manager for electromobility, manager of global repair parts, parts marketing manager and senior purchaser for battery area. Several documents were collected from the case company on a need-basis, which includes battery and purchasing related data, remanufacturing and repurposing documents, and EV forecast data. The gathered data through interviews, discussions, meetings, company documents, and theoretical papers used as a foundation for the data analysis.

\section{Results}

\subsection{Identifying the potential second life applications and final concept selection}

The case company is currently in the developing stages of hybrid and electric construction machines. The EV batteries are expected to be implemented in the year 2020 and the batteries might be available for a second life in the year 2025. Even though the expected service life is 5-15 years for the li-ion BPs, the company wants to prepare the initial infrastructure and related processes in order to enter the market as soon as possible.

The initial exploration resulted into nine different suggestions consisting of remanufacturing of li-ion battery pack, forklift, aftermarket, lawnmower, solar park (Battery to grid), ESS container, off grid (Home use), micro hydro power, and housing backup. After comparing and analysisng the technical details such as different battery types, its properties, dimensions etcetera, five ideas for a second life application were 
identified, including: Remanufacturing of li-ion BP, Lawn mower, Forklift, ESS, and Aftermarket. The Pugh's matrix was developed on five concepts, considering all relevant functions of the value chain such as market, logistic, manufacturing and sales. Using the matrix, three potential concepts were concluded based on their weighted total and criterions in the matrix, namely ESS, Remanufacturing of li-ion BP and the Aftermarket. Figure 2 illustrates the process map of the three concepts that were analysed and evaluated.

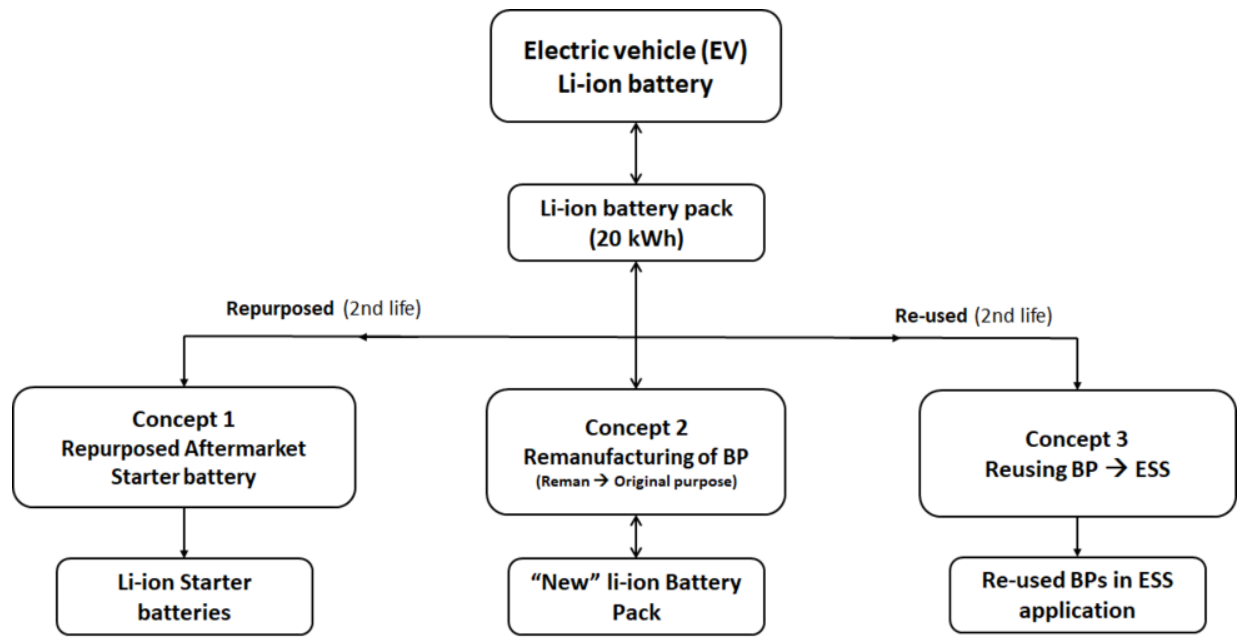

Figure2. Process map of the three selected concepts

\subsection{Results of the three generated concepts based on business model canvases}

The business model canvases were developed for the three concepts, considering financial aspects, key and customer variables, and marketing strategies. Figure 3 illustrates the business model canvas developed for concept 2 , remanufacturing of Li-ion battery packs.

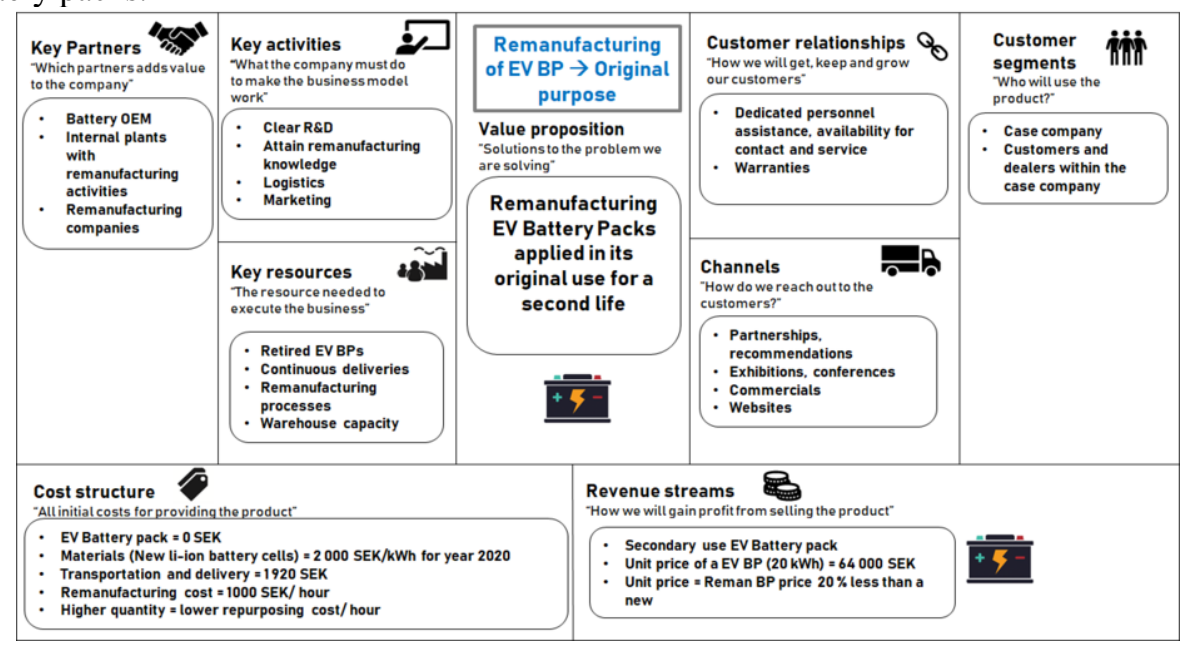

Figure3. Business model canvas of the remanufacturing concept 
From analysing the business model canvases for three concepts, the profit curves for three concepts were made from initial investment, which is 2023-2050, as shown in Figure 4. The $\mathrm{X}$ axis is the amount of years from 2023-2050, while the $\mathrm{Y}$ axis is million SEK. The reason for extending the amount of years in the $X$ axis shown in the diagram is mainly because the remanufacturing concept will pass the ESS concept in year 2042, which is an important event to illustrate. Explaining these different functions will determine which concept to prefer when three different investments are made, including their related profits of the investment.

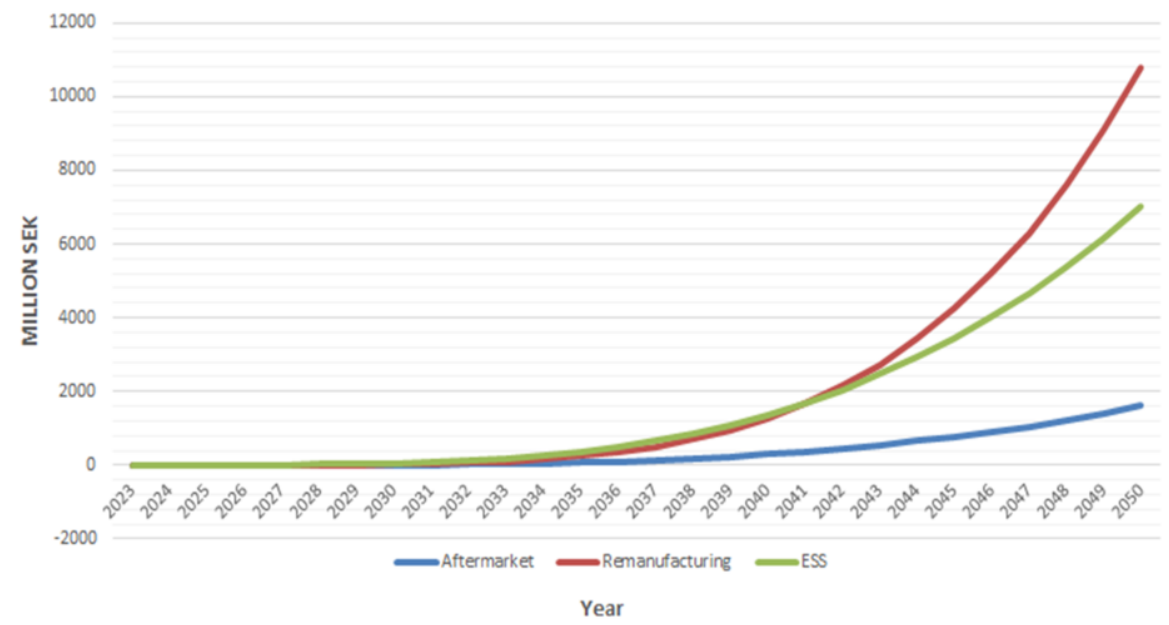

Figure4. Profit curves from the initial investment for all the three concepts

According to the profit curve, the Aftermarket concept (blue) demonstrates the lowest initial profit of investment compared to the other two concepts, since the unit price is the lowest out of the three concepts. The curve is more constant in its profit growth over time, however with a lower total profit.

For the Remanufacturing concept (red), the profit curve shows a drastic increase after 2040. The reason for such a drastic increase is since the unit price is indicating on a much higher price compared to the Aftermarket concept. This determined unit price is set since a remanufactured EV battery includes a complete cell exchange, making the battery as good as new and can therefore be sold to a similar price as a new EV BP. Another factor for the increase could also be due to including the decreasing value of the li-ion battery price in the calculations. This decreasing value has also been considered in the ESS concept but not in the Aftermarket concept where the material cost is constant. As the EV market forecast has been included in the calculations as well as the company's electrification percentage, the remanufacturing concept is considered to be a more suitable investment due to the significant future market increase.

Similarly, the ESS curve (green) shows a drastic increase as the remanufacturing concept. This is also connected to the high unit price for an entire ESS container, which is determined to be the highest of all the concepts. As the remanufacturing concept the ESS has a material cost that varies depending on the li-ion battery price decrease. Accordingly, ESS will have the shortest payback period and is predicted to be most profitable until year 2042, where the remanufacturing concept will exceed the ESS. 
In conclusion, all three concepts have illustrated a constant increment for the first 10 years while the Aftermarket concept remains constant, the remanufacturing and ESS concepts shows a substantial growth 10 years after the investment, from 2033 and onwards. This could highly depend on the market prediction that will most likely change and the decreasing li-ion price that has not been taken into consideration for the Aftermarket concept.

Figure 5 has been illustrated by the authors, to show the payback year for each concept. The ESS concept has the shortest payback year of 3 years, where it is expected to be profitable as early as in year 2025. For the remanufacturing concept it is expected to have a payback year of 5 years and will be profitable in 2027. Lastly, the Aftermarket concept requires 7 years until it is profitable, where the payback year is in 2030 .

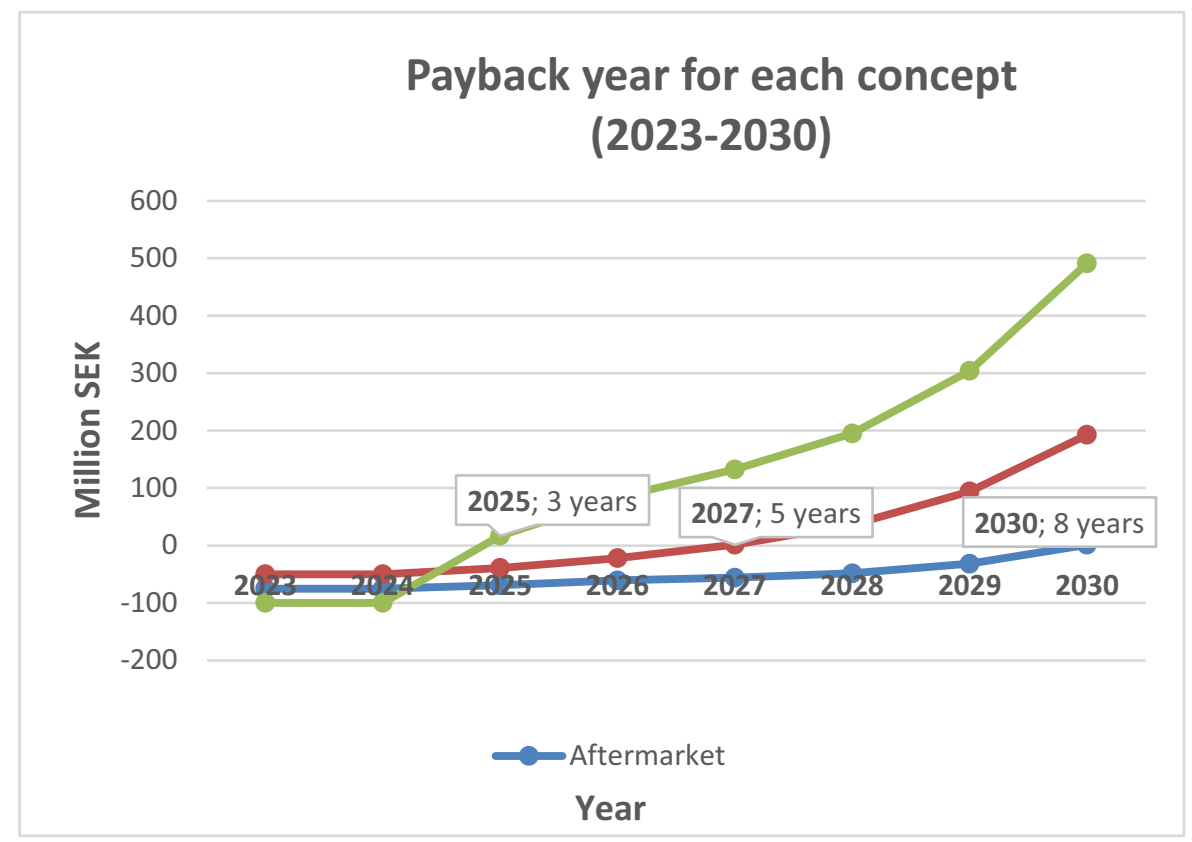

Figure5. Payback year for each concept from 2023 to 2030

In order to get a better holistic view out of the three concepts, the total profit with the calculated investment, annual return rate and payback years will all be presented for 5, 10 and 15 years after the investment. The table begins from 2023 since it is the year the investments are made and then it calculates the expected results 5, 10- and 15-years forwards and is used to conclude which concept is preferred to invest in. According to the data in the table below, the ESS will be the most profitable concept in a 15 -year period, with the highest overall profit and the shortest payback time. 
Table 1. The illustration of total profit, RR, payback year and the overall conclusion of the three concepts in a 15 -year period

\begin{tabular}{|c|c|c|c|c|c|c|c|c|c|}
\hline & \multicolumn{3}{|c|}{5 years -2028} & \multicolumn{3}{|c|}{10 years -2033} & \multicolumn{3}{|c|}{15 years -2038} \\
\hline & AM & REMAN & ESS & AM & REMAN & ESS & AM & REMAN & ESS \\
\hline $\begin{array}{l}\text { Total profit, } \\
\text { (Million SEK) }\end{array}$ & $-48,5$ & 36,2 & 195,1 & 275,8 & 1023,9 & 1842,8 & 1782,3 & 7082,4 & 8654,9 \\
\hline Return Rate, $\%$ & $-36,8$ & $-7,0$ & $-8,9$ & 5,5 & 23,2 & 19,9 & 12,6 & 27,8 & 22,0 \\
\hline Payback year, (year) & 7 years & 5 years & $\begin{array}{l}3 \\
\text { years }\end{array}$ & 7 years & 5 years & 3 years & $\begin{array}{l}7 \\
\text { years }\end{array}$ & 5 years & 3 years \\
\hline Overall conclusion & $\begin{array}{l}\text { Reman } \\
\text { AM ha }\end{array}$ & $\begin{array}{l}\text { uring ha } \\
\text { longest }\end{array}$ & $\mathrm{tR}$ & $\begin{array}{l}\text { le ES } \\
\text { is le }\end{array}$ & $\begin{array}{l}\text { is the sh } \\
\text { orofitabl }\end{array}$ & b & he an & h & \\
\hline
\end{tabular}

From table, it is evident that the Aftermarket concept will be excluded mainly considering that it does not meet the requirements regarding the payback years. It further has a low profit and RR in comparison to the other concepts.

If the selection is primarily based on the data that is presented in the table above, the ESS concept is a good alternative to strive for. Consequently, a clarification towards the ESS concept is that the research area is not something that the company has worked with earlier, which will essentially require a lot of commitment, time and money to prove that the concept is worth to invest in. From a realistic perspective, the remanufacturing proposal might be a reasonable option for the company. The remanufacturing concept will require 2 more years in order to gain profit from the investment made in comparison to the ESS. However, the remanufacturing concept might have a longer payback period but is more appropriate from a company perspective, seeing that the concept will surpass ESS in year 2042 in the long-term aspect. Meanwhile from a short-term investment, the ESS is the better alternative considering a faster and higher profit in the beginning.

The Remanufacturing application concept is already a common process that is utilized within the company. By that indication it is a great advantage in the features of having knowledge in the related area. This facilitates the learning process of remanufacturing when the company already has ongoing operations in this field. Therefore, the concept will substantially be kept internal if it is manageable with less focus on the external remanufacturing companies. From a second life prospect, the remanufacturing method is a better alternative, due to the exchange of li-ion cells in the batteries that are implemented while no repurposing or remanufacturing is performed for the ESS concept.

From all the presented factors regarding the benefits and drawbacks for each concept, the study concluded that the selection of the Remanufacturing application concept is more suitable from a company perspective while also being profitable. The selection is based on all calculated numbers from the empirical findings including investment, total costs, payback years, return rate and profit factors within a range of 15 years. Further, the study suggests that a good starting point would be to perform the remanufacturing processes in the current remanufacturing facility in Sweden. The facility already has knowledge in remanufacturing processes and the required equipment and tools. These factors were the main reasons why the investment cost for the concept was lower than the other two concepts.

\section{Conclusions and limitations}

In the intial stage, the study concluded three second life concepts as the most feasible for the company's requirements. These concepts consisted of Aftermarket options, involving a repurposing process of a $20 \mathrm{kWh}$ battery pack (BP) transitioning it to 11 starter batteries 
with an energy capacity of $1,7 \mathrm{kWh}$ per starter battery. The second concept was the Remanufacturing of the BP for its original purpose. The process implies in a total battery cell replacement for the BP. Lastly, the third concept was the re-use of BP for an ESS application. One ESS container has an energy capacity of $4000 \mathrm{kWh}$ implicating on that $200 \mathrm{BPs}$ are required to manage the specific energy capacity in the container. This concept signifies that no repurposing or remanufacturing process is required and that a re-use is achieved.

From the empirical analysis, the remanufacturing application concept proved to be the most economically viable second life option. The economic aspect, involving: total profit with investment, payback year and return rate were the determining factors for the selection of the concept. The study investigated a 15-year period to identify the differences between the three concepts and their profitability in the long-term.

The study gives an estimate of the chosen concepts and provides an overall picture of these concepts. The study had delimited three concepts into a final one. Although the ESS and Aftermarket were not appropriate for the company, it does not imply that the concepts are not feasible from a second life perspective. It only implicates that the Remanufacturing concept was most suitable for the company in this case. Currently, second life of EV batteries have not adopted in a broader scope, and new EV batteries have not ended its first life yet. The selected concept is adapted to the company therefore, it may be difficult for other companies to follow the same procedure. Some of the composed numbers were based on research and assumptions and but it should instead be collected from real cases from companies. This will create more realistic calculations for the company in its future application. Further, in future, calculated numbers in the study needs to be updated when using the second life applications, which will provide more continuous reliable data. Additionally, the development of new battery technologies will replace the current battery technology and will change the current calculations and recommended application concepts. Future studies need to consider this aspect. A further recommendation is to develop an economical calculation for the reverse logistic and recycling process, to strengthen the second life concepts even further.

\section{References}

[1] European Commission, Roadmap to a Single European Transport Area - Towards a competitive and resource efficient transport system. White paper, Brussels, 2011.

[2] Johansson T, Fossilfrihet på väg SOU 2013: 84. Stockholm, Statens offentliga utredningar (1000 s); 2013.

[3] Global Forecast Report, Electric Vehicle Market by Propulsion (BEV, PHEV, FCEV), Vehicle, Charging Station (Normal, Super, Inductive), Global Forecast to 2025, ID: 4580165, 2018.

[4] Bloomberg NEF report, Electric Vehicle Outlook, 2019.

[5] Winslow, K.M., Laux, S.J. and Townsend, T.G, A review on the growing concern and potential management strategies of waste lithium-ion batteries, Resources, Conservation and Recycling, vol. 129, 2018, pp. 263-277.

[6] Olsson, L., Fallahi, S., Schnurr, M., Diener, D. and Van Loon, P, Circular business models for extended EV battery life, Batteries, vol. 4, no.4, 2018, pp. 57.

[7] Foster, M., Isely, P., Standridge, C.R. and Hasan, M.M, Feasibility assessment of remanufacturing, repurposing, and recycling of end of vehicle application lithium-ion batteries, Journal of Industrial Engineering and Management, vol. 7, no.3, 2014, pp. 698-715.

[8] Casals, L, C., Barbero, M. and Corchero, C, Reused second life batteries for aggregated demand response services, Journal of Cleaner Production, vol. 212, 2019, pp. 99-108.

[9] Willuhn, M, Second-life EV battery market to grow to $\$ 4.2$ billion by 2025 . PV Magazine, 2018.

[10] Reid, G. and Julve, J, Second life-Batteries as flexible storage for renewables energies, Digital Energy Report, Berlin, 2016. 
[11] Melin, H, E, The lithium-ion battery end-of-life market - A baseline study, Circular Energy Storage report, 2018.

[12] Golembiewski, B., vom Stein, N., Sick, N., Wiemhöfer, H-D, Identifying trends in battery technologies with regard to electric mobility: evidence from patenting activities along and across the battery value chain, Journal of Cleaner Production, vol. 87, no.1, 2014, pp. 800-810.

[13] Roth, P. and Orendorff, C, J, How Electrolytes Influence Battery Safety, The Electrochemical Society Interface, 2012.

[14] Rezvanizaniani, M.S., Liu, Z., Chen, Y., Lee, J, Review and recent advances in battery health monitoring and prognostics technologies for electric vehicle (EV) safety and mobility, Journal of Power Sources, vol. 256, no.1, 2014, pp. 110-124

[15] Klör, B., Bräuer, S. and Beverungen, D, A business process model for the reverse logistics of used electric vehicle batteries, In: Informatik Conference, Stuttgart, 2014, pp. 1631-1643.

[16] Rohr, S., Wagner, S., Baumann, M., Muller, S. and Lienkamp, M, A Techno-Economic Analysis of End of Life Value Chains for Lithium-Ion Batteries from Electric Vehicles, In: Twelfth International Conference on Ecological Vehicles and Renewable Energies (EVER), Monaco, 2017, 11-13 April.

[17] Catton, J., Walker, S.B., Mclnnis, P., Fowler, M., Fraser, R., Young, S.B. and Gaffney, B, Comparative Safety Risk and the Use of Repurposed EV Batteries for Stationary Energy Storage, In: IEEE International Conference on Smart Energy Grid Engineering (SEGE), Canada, 14-17 Aug. 2017, pp. 200-209.

[18] Standridge, C. and Corneal, L, Remanufacturing, repurposing and recycling of postvehicle-application lithium-ion batteries, Mineta National Transit Research Consortium (MNTRC), 2014, pp. 1-57.

[19] Martinez-Laserna, E., Gandiaga, I., Sarasketa-Zabala, E., Badeda, J., Stroe, D.-I. Swierczynski, M. and Goikoetxea, A, Battery second life: Hype, hope or reality? A critical review of the state of the art, Renewable and Sustainable Energy Reviews, vol. 93, 2018, pp. 701-718.

[20] Bocken, N, M,P., de Pauw, I., Bakker, C. and van der Grinten, B, Product design and business model strategies for a circular economy, Journal of Industrial and Production Engineering, vol. 33, no.5, 2016, pp. 308-320.

[21] Osterwalder, A., Pigneur, Y., In Clark, T. and Smith, A. Business model generation: A handbook for visionaries, game changers, and challengers, John Wiley and Sons, USA, 2010.

[22] Jiao, N. and Evans, S, Business Models for Sustainability: The Case of Repurposing Electric Vehicle Batteries, In: $13^{\text {th }}$ Global Conference on Sustainable Manufacturing, Vietnam, April 2017, pp. 250-255.

[23] Naor, M., Druehl, C. and Bernardes, E. S, Servitized business model innovation for sustainable transportation: Case study of failure to bridge the design-implementation gap, Journal of Cleaner Production, vol. 170, 2018, pp. 1219-1230.

[24] Yin, K. R, Case Study Research - Design and Methods, Sage publications, California, 2014.

[25] Bryman, A. and Bell, E, Business Research Methods, Oxford University Press, New York, 2015. 